\title{
ERECTILE DYSFUNCTION AND ITS PHARMACOLOGY: AN OVERVIEW
}

\author{
SUNIL KUMAR PATNAIK*, POLIMATI HARITHA, RAJESWARA RAO P
}

Department of Pharmacology Division, Andhra University College of Pharmaceutical Sciences, Andhra University, Visakhapatnam, Andhra Pradesh, India.Email: prsunilkumarpatnaik@gmail.com

Received: 14 September 2016, Revised and Accepted: 01 November 2016

ABSTRACT

It has been estimated that currently over 150 million men worldwide suffer from erectile dysfunction (ED) and by 2025 , the figure will increase beyond 322 millions. ED is the inability to achieve, and/or maintain penile erection sufficient for satisfactory sexual intercourse, and was previously regarded as the part of aging. It is associated with certain diseases and life style habits with a cause-effect relationship, including diabetes mellitus, hypertension, dyslipidemia, and cigarette smoking. Internationally, most of the men with ED fail to pursue treatment due to the complex nature of sexuality, taboos, cultural restrictions, and acceptance of ED as a normal sequel of aging. In this review, we discussed the physiology, diagnosis, and risk factors associated with ED and current treatment strategies for ED.

Keywords: Erectile dysfunction, Diabetes, Penile erection, Phosphodiesterase inhibitors.

(C) 2017 The Authors. Published by Innovare Academic Sciences Pvt Ltd. This is an open access article under the CC BY license (http://creativecommons. org/licenses/by/4. 0/) DOI: http://dx.doi.org/10.22159/ajpcr.2017.v10i2.15183

\section{INTRODUCTION}

Penile erection is an integrated part of male sexual behavior and is dependent on coordinated activities in the central and peripheral nervous systems, as well as on intact inter- and intra-cellular signaling pathways in the penis. Erectile dysfunction (ED) is next only to premature ejaculation in prevalence among male sexual problems [1]. However, it is known that medical practitioners often do not inquire about it in patients in whom it may not be the complaint [2]; even though, risk factors for it may be present; especially hypertension, use of antihypertensive drugs, diabetes mellitus, and smoking [3]. This situation is surprising because ED has a major negative impact on quality of life [4] and for this reason, it has been suggested that even if patients do not mention ED problems, physicians should not neglect to inquire about them [5]. It has been estimated that currently over 150 million men worldwide suffer from ED and by 2025, the figure will increase beyond 322 millions [6]. The prevalence of ED increases significantly with age, from approximately $10 \%$ between age 40 and 49 years to over $50 \%$ after age $>70$ years [7].

\section{PHYSIOLOGY}

Penile erection is a complex neurovascular event involving the interaction between different systems: The nervous system (central and peripheral) and the penile (arterial and trabecular) smooth muscle system. The tone of penile smooth muscle is a key determinant of the hemodynamic events that maintain penile flaccidity or allow erection. The cavernosal arteries supply blood to the corpora cavernosa of the penis (through the pudendal artery), whereas the emissary veins running through the tunica albuginea allow blood to flow out of the penis. In the flaccid penis, smooth muscle cells of corpora cavernosa are contracted and penile blood inflow is low. During erection, relaxation of trabecular smooth muscle results in an increased blood flow and pressure in the corpora cavernosa and an expansion of sinusoidal spaces (Fig. 1). The expanded corpora cavernosa cause mechanical compression of the emissary veins, restricting the venous outflow from the cavernosal spaces and facilitating an entrapment of blood in the cavernosal sinusoids. This blood engorgement finally results in penile rigidity [8].

Several neurotransmitters and endothelial factors have been shown to control erectile function by modulating the penile vasculature and smooth muscle tone of corpora cavernosa [9]. The correct balance between relaxant and contractile factors is required to determine the functional state of the penis, finally resulting in a normal erectile function.

\section{DIAGNOSIS AND RISK FACTORS}

Diagnosis is best done by means of a detailed sexual history. The second is to ascertain the severity of the problem. This can be done objectively with questionnaires, for example, international index of erectile function (IIEF) [10] or it can be ascertained from the history. The third is to identify treatable conditions that may be relevant to the cause of the ED. Such conditions might include diabetes, hyperlipidemia, depression, hypertension, or hypogonadism (Table 1). Some of these conditions will be identified during history and examination, whereas others will require special investigations. The fourth objective is to identify patients who have causes of ED which might be amenable to specific treatment (Table 2) and also by physical examination (Table 3). The following sections will give a survey of the clinical studies that have addressed the possible role played by diabetes, cardiovascular diseases (CVD), obesity, and smoking in the development of ED.

\section{DIABETES}

Diabetes is associated with accelerated large vessel atherosclerosis and microvascular arterial disease, autonomic neuropathy, dyslipidemia, concomitant hypertension, and endothelial dysfunction. Diabetic men are 3 times as likely to develop ED as non-diabetic men. The cause is multifactorial, but most commonly reflects endothelial dysfunction and autonomic neuropathy. In a recent prevalence and risk factors analysis for ED using the IIEF-5, in men aged 20-80 years undergoing a health investigation, it was shown that $32.2 \%$ of men had ED according to the IIEF-5 and that the most important risk factor was diabetes [11]. ED in diabetes may be secondary to a neuropathic condition of the autonomic penile nerves. Indeed, it has been shown that there is a functional penile neuropathic condition of the cholinergic nerves in the corpus cavernosum of diabetic impotent patients that may be responsible for the ED.

This relationship between autonomic neuropathy and impotence in diabetes was studied in human tissue obtained during implantation 
Table 1: Common organic risk factors for ED

\begin{tabular}{ll}
\hline Vascular disease & Atherosclerosis \\
& Hypertension \\
& Hyperlipidemia \\
& Diabetes mellitus \\
& Multiple sclerosis \\
& Spinal cord injury \\
Neurological disease & Pelvic nerve injury secondary to pelvic \\
& fracture \\
& Hypogonadism \\
Endocrine disease & Hyperprolactinemia \\
& Diabetes mellitus \\
Psychiatric and & Depression \\
Psychological disease & Anxiety disorders \\
Iatrogenic ED & Surgical damage to pelvic nerves \\
& (e.g., during radical prostatectomy) \\
& Radiotherapy for pelvic malignancy \\
& Drugs \\
& Renal failure \\
Multifactorial problems & Aging \\
&
\end{tabular}

ED: Erectile dysfunction

Table 2: Drugs that can cause erectile dysfunction

\begin{tabular}{|c|c|}
\hline Antidepressants & $\begin{array}{l}\text { Imipramine } \\
\text { Doxepin } \\
\text { Trazodone } \\
\text { Isocarboxazid } \\
\text { Desipramine } \\
\text { Protryptiline } \\
\text { Maprotiline } \\
\text { Nortryptiline } \\
\text { Clomipramine } \\
\text { Tranylcypromine } \\
\text { Amitriptyline } \\
\text { Amoxapine } \\
\text { Phenelzine }\end{array}$ \\
\hline Antipsychotics & $\begin{array}{l}\text { Chlorpromazine } \\
\text { Thioridazine } \\
\text { Pimozide } \\
\text { Sulpiride } \\
\text { Thiothixene } \\
\text { Haloperidol } \\
\text { Fluphenazine }\end{array}$ \\
\hline Antihypertensives & $\begin{array}{l}\text { Hydrochlorothiazide } \\
\text { Reserpine } \\
\text { Propanolol } \\
\text { Guanadrel } \\
\text { Spironolattone } \\
\text { Guanethidine } \\
\text { Chlorthalidone } \\
\text { Labetalol } \\
\text { Alpha-methyldopa } \\
\text { Clonidine } \\
\text { Guanabenz } \\
\text { Atenolol }\end{array}$ \\
\hline Drugs of abuse & $\begin{array}{l}\text { Alcohol } \\
\text { Cocaine } \\
\text { Amphetamines }\end{array}$ \\
\hline Anticonvulsants & $\begin{array}{l}\text { Barbiturates } \\
\text { Phenytoin } \\
\text { Primidone } \\
\text { Carbamazepine }\end{array}$ \\
\hline Miscellaneous & $\begin{array}{l}\text { Cimetidine } \\
\text { Ketamine } \\
\text { Metadone } \\
\text { Digoxin } \\
\text { Lithium } \\
\text { Thiabendazole } \\
\text { Clofibrate } \\
\text { Acetazolamide } \\
\text { Disulfiram } \\
\text { Ketoconazole }\end{array}$ \\
\hline
\end{tabular}

of a penile prosthesis in 19 impotent diabetic and 15 non-diabetic patients. The functional status of penile cholinergic nerves was assessed by evaluating acetylcholine accumulation, synthesis, and release using tritiated choline. Tritiated choline accumulation and tritiated acetylcholine synthesis and release were significantly reduced in the corporeal tissue from diabetic patients compared to that from non-diabetic patients, and no differences were found between insulindependent and non-insulin-dependent diabetic patients [12].

\section{CVD}

There are several pieces of evidence in preclinical pharmacology and in clinical pharmacology that CVD represent a risk factor for ED. It is now generally accepted that the prevalence of CVD, such as ED, increases with age, but CVD by themselves are one of the major risk factor for ED. Overall, atherosclerotic vascular disease can account for almost $50 \%$ of the ED in men over 50 years of age. Heart disease and its associated risk factors, such as hypertension and low serum high density lipoprotein cholesterol, are significantly correlated with ED as demonstrated in the Massachusetts Male Aging study [13]. However, at present, there is an increasing interest in the possibility that ED represents an early sign of the existence of CVD, and that diagnosis of ED in an otherwise healthy patient could be considered an indication of a more systemic endothelial and vascular dysfunction.

\section{Obesity}

Healthy lifestyle factors are associated with maintenance of erectile function in men and there are several studies that have correlated life-style with ED. In an early study conducted in 1999 by Chung [14], ED was evaluated in 325 patients that were classified into 2 groups according to body weight: $<120 \%$ and $120 \%$ of the ideal body weight. In this study, several erectile capacities were compared and a penile duplex ultrasonography analysis performed. In patients with obesity, there was a statistically significant decrease in the quality of residual erectile function measured as penile rigidity. Interestingly, 43\% of the obese patients also displayed a significantly increased prevalence of vascular risk factors versus $30 \%$ in the non-obese, and $62 \%$ of the obese patients displayed a significant vascular impairment as assessed by duplex ultrasound versus $42 \%$ in the non-obese patients. However, when only the patients without any vascular risk factors were analyzed, no significant difference between the 2 groups was noted in the quality of residual erectile function and in the prevalence of penile vascular impairments ( $p>0.05)$, suggesting that obesity in itself does not seem to be an underlying factor, but does impose a risk to vasculogenic impotence by promoting development of chronic vascular disease.

\section{Smoking}

It is important to point out that virtually every part of the body, including the urological system, is adversely affected by smoking. Smoking is a powerful predictor of ED; however, cessation may restore normal function. Cigarette smoke also exerts adverse effects on sperm motility and count [15]. At the molecular level, several changes associated with smoking have been documented in man. In particular, it has been shown that smoking causes an impaired penile flow. Cigarette smoking also interferes with the potency of intracavernous papaverine and prostaglandin E1 (PGE1), clearly indicating that smoking reduces not only endothelial function but also smooth muscle response [16].

\section{TREATMENT}

\section{First-line therapy}

\section{Oral medications}

The introduction of phosphodiesterase type 5 inhibitors (PDE5Is) in 1998, has clearly revolutionized the management of ED. Oral pharmacotherapy PDE5 is an enzyme that hydrolyzes cyclic guanosine monophosphate in the cavernosum tissue of the penis. Inhibition of PDE5 results in increased arterial blood flow leading to smooth muscle relaxation, vasodilatation, and penile erection. Three potent selective PDE5 inhibitors are currently licensed with proven efficacy and safety for the treatment of ED. 
Sildenafil

Sildenafil was the first PDE5 inhibitor and $>20$ million men have been treated in the 6 years since its launch. It is effective (erection with rigidity sufficient for vaginal penetration) after 30-60 minutes from administration [17]. Its efficacy is reduced after a heavy fatty meal (reduced, i.e., prolonged absorption). It is administered in doses of 25, 50 , and $100 \mathrm{mg}$. The recommended starting dose is $50 \mathrm{mg}$ and adapted according to the response and side effects. Efficacy may be maintained for up to $12 \mathrm{hrs}$ [18].

Tadalafil

Tadalafil is effective from 30 minutes after administration, but its peak efficacy is expected in about $2 \mathrm{hrs}$ [19]. Efficacy is maintained for up to $36 \mathrm{hrs}$ [20]. Its efficacy is not influenced by food. It is administered in 10 and $20 \mathrm{mg}$ doses. The recommended starting dose is $10 \mathrm{mg}$ and is adapted according to the response and side effects.

Vardenafil

Vardenafil is effective after 30 minutes from administration. Its effect is reduced by a heavy fatty meal ( $>57 \%$ in fat). It is administered in 5,10 , and $20 \mathrm{mg}$ doses [21]. The recommended starting dose is $10 \mathrm{mg}$ and is adapted according to the response and side effects. In vitro, it is 10 -fold more potent than sildenafil; however, this does not necessarily imply greater clinical efficacy [22]. Adverse events are generally mild in nature and self-limited by continuous use.

\section{Contraindications}

Concomitant (e.g., within $24 \mathrm{hrs}$ for sildenafil and vardenafil, and $48 \mathrm{hrs}$ for tadalafil) use of nitrate-containing medications (e.g., nitroglycerin, isosorbide dinitrate) is an absolute contraindication to PDE5Is use, as it can cause severe hypotension that can result in death. PDE5Is for patients who have recent serious cardiac events, poorly controlled hypertension, unstable angina or retinitis pigmentosa should be used with caution [23]. Coexisting cardiac conditions including stable coronary artery disease and heart failure do not post higher risk of cardiac ischemia, coronary vasoconstriction or worsening of the hemodynamic profile on exertion $[24,25]$.

\section{Adverse events}

Adverse events for all three PDE5Is are generally mild and well-tolerated. Common side effects are similar for all three PDE5Is (Table 4). These include headache, flushing, dyspepsia, and nasal congestion. Other side effects specific to individual drug include musculoskeletal pain (3-6\% with tadalafil), changes in color perception and light sensitivity (sildenafil and vardenafil) [26]. These visual changes are due to crossover effects of the drugs on PDE6, an isoform of PDE in the retina. A significantly more severe visual adverse event recently associated with PDE5Is is non-arteritic ischemic optic neuropathy, known to be the most common acute optic neuropathy and ranks second only to glaucoma as a cause of acquired optic neuropathy that can lead to sudden blindness.

Data are from the European Medicine Evaluation Association statements on product characteristics.

\section{Apomorphine}

Apomorphine is a centrally acting drug (dopamine agonist, mainly D2) that improves erectile function by enhancing the natural central erectile signals that normally occur during sexual stimulation. It is administered sublingually on demand in 2 or $3 \mathrm{mg}$ doses. Apomorphine has been approved for ED treatment in many countries but not in the United States. Efficacy rates (erections hard enough for intercourse) range from $28.5 \%$ to $55 \%$ [27]. Due to rapid absorption, $71 \%$ of erections are achieved within 20 minutes. The most common adverse events are nausea (7\%), headache (6.8\%), and dizziness (4.4\%).

\section{Topical pharmacotherapy}

Several vasoactive drugs (2\% nitroglycerin, $15-20 \%$ papaverine gel, and $2 \%$ minoxidil solution or gel) have been used for topical application
Table 3: Critical aspects of the physical examination

\begin{tabular}{|c|c|}
\hline Genitalia & $\begin{array}{l}\text { Size and shape of penis } \\
\text { Abnormalities of the prepuce including } \\
\text { phimosis } \\
\text { Palpable plaque signifying Peyronie's disease } \\
\text { Absent or small testes }\end{array}$ \\
\hline Secondary sexual & Body habitus \\
\hline characteristics & $\begin{array}{l}\text { Gynaecomastia } \\
\text { Appropriate hair distribution } \\
\text { Body fat distribution }\end{array}$ \\
\hline Vascular system & Blood pressure assessment \\
\hline
\end{tabular}

Table 4: Common adverse events of the three PDE5 inhibitors

\begin{tabular}{llll}
\hline Adverse event & Sildenafil (\%) & Tadalafil (\%) & Vardenafil (\%) \\
\hline Headache & 12.80 & 14.50 & 16 \\
Flushing & 10.40 & 4.10 & 12 \\
Dyspepsia & 4.60 & 12.30 & 4 \\
Nasal & 1.10 & 4.30 & 10 \\
congestion & & & \\
Dizziness & 1.20 & 2.30 & 2 \\
Abnormal & 1.90 & - & $<2$ \\
vision & & & \\
Back pain & - & 6.50 & - \\
Myalgia & - & 5.70 & - \\
\hline
\end{tabular}

PDE5: Phosphodiesterase type 5

to the penis [28]. Adverse events include skin and glans erythema, burning sensation, allergic reactions, and side effects to the partner (hypotension, headache) due to absorption from the vagina.

\section{Vacuum constriction device}

This ED therapy functions via mechanical rather than pharmacological mean. It includes a plastic cylinder connecting to a vacuum-generating source powered manually or by battery. When placed on the penis, negative pressure provokes engorgement of blood to the sinusoidal tissue of the penile shaft and glands. An elastic ring is applied to the base of the penis to prevent egress of the trapped blood to enhance the rigidity for sexual activity. Despite several advantages such as no systemic side effects, high efficacy, low cost per treatment (after the initial expense for the device), the satisfaction rate of this device was only about $60-80 \%$ with a significant drop-out rate [29-31].

\section{Second-line therapy}

Intracavernosal injection

Available since the 1980 s, intracavernous injection with single or combination vasoactive agents (commonly alprostadil, papaverine, phentolamine, and moxisylyte) was once the most frequently used therapies for ED before the PDE5Is' era. Currently, for ED cases refractory PDE5Is (e.g. post-radical prostatectomy, severe diabetes or CVD) or when PDE5Is are contraindicated, intracavernous injection remains an effective ED treatment, either alone or in conjunction with other ED therapies such as PDE5Is. Proper selection of candidates (e.g., adequate dexterity for needle manipulation, absence of bleeding diathesis, etc.) and proper education is the key to successful treatment with intracavernous injection.

\section{Transurethral medication}

Alprostadil used in intracavernous injection can be applied transurethrally at a higher dose $(250-1000 \mu \mathrm{g})$ as a therapy for ED with a success rate of 40-69\% [32-35]. Adverse events associated with transurethral alprostadil include urethral pain and injury, vasovagal reflex, hypotension, and priapism $(<0.1 \%)$. Although it devoid the need of needle injection, its effectiveness is significantly lower than when administered intracavernously. The use of penile constriction ring at the base has been advocated to enhance the efficacy of transurethral 
alprostadil and to reduce the risks of hemodynamic adverse events by slowing the rate of systemic absorption of the drug [36].

\section{Testosterone replacement therapy}

Androgens regulate erectile physiology via multiple mechanisms [37]. The decline in serum bio-available testosterone with aging can contribute to the severity of ED. When properly diagnosed and treated, testosterone replacement has been shown to be safe and effective in enhancing sexual desire and the efficacy of other forms of ED therapies $[38,39]$. Testosterone replacement can be administered transdermally, orally, intramuscularly or via buccal mucosa.

\section{Penile prosthesis}

The insertion of a penile prosthesis, which can be either a semirigid/malleable type made of silicone rubber with a central intertwined metallic core or hydraulic prosthesis that can be inflated or deflated through activation of scrotal pump controlling water flow from a suprapubic reservoir to the cylinders placed inside the corporal bodies of the penis, can virtually guarantee an erection for successful intercourse [40]. The surgical technique of penile prosthesis placement has been significantly modified and most experts can perform it with a single longitudinal incision through the ventral part of the penis as an outpatient procedure [41]. Large studies demonstrated a satisfaction rate $>95 \%[42]$

There is little interference in the orgasm, ejaculatory or urinary function, particularly with the hydraulic prosthesis. Mechanical failure of the prosthesis can occur, particularly with the hydraulic prosthesis, at a rate of $5-20 \%$ in the first 5 years [23]. Infection rate of penile prosthesis has been reduced in the recent years as a result of improved surgical techniques, use of prophylactic antibiotics and modification of the prosthesis materials that allow for antibiotic impregnation and elution. It should be noted that placement of penile prosthesis is irreversible as the corporal tissue is permanently altered, making it not possible to achieve physiologic erection. Thus, candidates for this surgical therapy for ED should be carefully selected and counseled.

\section{Sex therapy}

Before 1970s, individual psychotherapy was the typical treatment for sexual dysfunction. Evidently, ED can be a cause and a consequence of psychosocial stress. Many of the approaches developed in the 1980s and 1990s are still currently in use. These include behavioral therapy, dual-sex therapy of Masters and Johnson, corporal approach, hypnotherapy, and group therapy. With the introduction of effective Pharmaco therapies, particularly the PDE5Is, the use of sex therapy for ED has clearly declined worldwide. Sex therapy, however, still plays an important role for other forms of sexual dysfunction including premature ejaculation, desire, arousal and orgasm problems, and other less common disorders.

\section{Some natural products in treatment of erectile-dysfunction activity}

Despite the world-wide interest in Viagra and the influence it has had on the search for a natural product which can deal effectively with the problem of ED, no such breakthrough has become a reality. Herbal medicines are widely available and are often used because of the belief that they are a safe alternative to conventional medication.

\section{Dehydroepiandrosterone (DHEA)}

DHEA is the major secretory steroidal hormone of the adrenal gland and its isolation dates back to 1934. In a comprehensive study [43] of 17 hormones it was shown that only DHEA showed a strong inverse

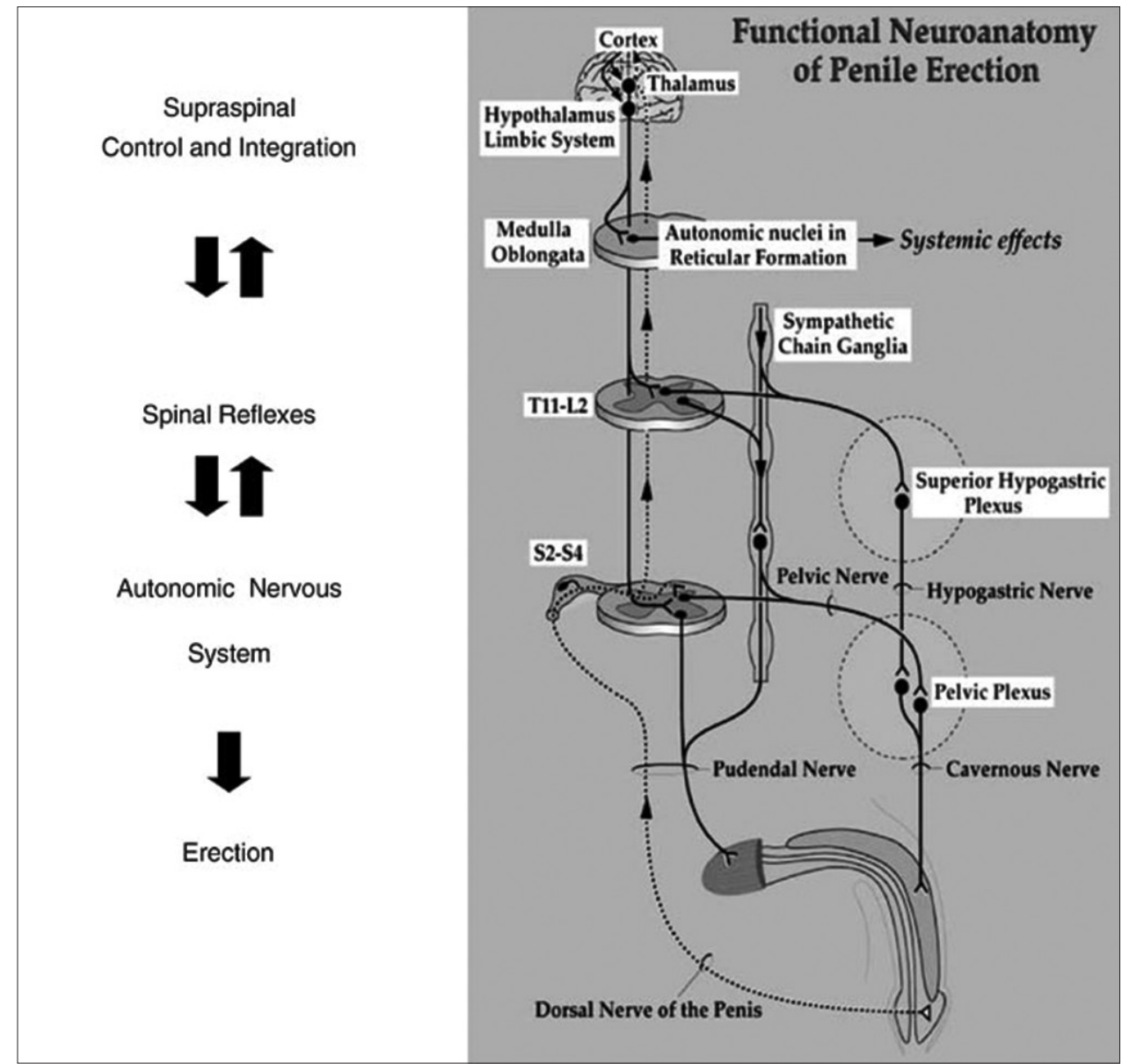

Fig. 1: Schematic representation of neurofunctional anatomy of penile erection 
correlation to E-D. A more recent investigation [44], was carried out on 40 men of mean average age 56 to study the effects of DHEA on patients with ED. The results suggest that daily oral supplementation of the hormone produces a rise in serum levels of DHEA, concomitant with increase in sexual performance and satisfaction.

\section{Yohimbine}

Yohimbine is an indole alkaloid with $\alpha_{2}$-adrenergic blocking activity. It comes from the bark of Corynanthe yohimbe and its first isolation was in the early 1930s. The bark of the tree is traditionally used to enhance sexual prowess and virility. Renewed interest in yohimbine for E-D has prompted several new investigative (including chemical) trials. Indications are that in some cases yohimbine can improve sexual performance [45]. There are, however, indications of undesirable sideeffects such as hypertension, anxiety, manic symptoms, and undesirable interactions with commonly used medications [46].

\section{-Citrulline}

When l-citrulline [(N5-aminocarbonyl)-l-ornithine] is part of a formulation with calcium phosphate and other extenders, it is marketed under the trade name STIMULIN. The preparation is claimed to improve sexual stamina and ease E-D. The active ingredient in the formulation is l-citrulline which occurs naturally in watermelons. L-citrulline was first isolated in the 1930 s, but its use as dietary supplement is of relatively recent origin. The activity of l-citrulline is attributed to its ability to release NO which, in turn, results in increased blood flow to the body, including the penis.

\section{Berberine}

Berberine is an alkaloid widely distributed in nature and occurs in Berberis plants such as Berberis aristata and Berberis vulgaris have undertaken a very detailed study on the relaxation of the corpus cavernosum and raised intravenous pressure by berberine in rabbit. For these tests, male New Zealand rabbits were used to obtain the corpus cavernosum tissue and the intravenous pressure change measured after intercavernosal injection of berberine. The overall results show that berberine possesses a relaxant effect on the rabbit corpus cavernosum tissue which is attributable to both endothelialdependent and -independent properties.

\section{Papaverine and prostaglandin E1}

A combination of two natural products from Papaver somniferum and from sheep seminal vesicle tissue, respectively, has received renewed attention as a potential combination against male impotence [47]. It should be emphasized that both papaverine and prostaglandin E1 are recognized vasodilators. Research findings based on a clinical trial on 100 impotent male patients indicated that papaverine plus PGE1 was more effective than PGE1 alone. The procedure was not without its complications, however, and reinforced the earlier findings [48] that papaverine, phentolamine, and PGE1, as a combination gave rise to side effects such as priapism [49] (extended erection), local fibrosis, and pain.

\section{Forskolin}

The source in nature of the diterpene forskolin is the Indian herb Coleus forskohlii. It is of relatively recent origin (1977) and possesses vasodilatory and cardiostimulatory properties. In view of the cyclic adenosine monophosphate dependent effects produced by forskolin, it has found use as an agent for the treatment of congestive cardiomyopathy, glaucoma, and asthma. Forskolin has also been investigated as an intracavernosal vasoactive agent in the management of vasculogenic impotence. In in-vitro tests, forskolin and PGE1 alone caused concentration dependent relaxation. Combination of the two agents resulted in synergistic response [50]. Clinical investigation in 31 patients showed no adverse effects. Overall $61 \%$ of these reported improvement in rigidity of the penis and/or erection duration using a combination of forskolin, papaverine, phentolamine, and PGE1.

\section{Tribulus terrestris}

T. terrestris (devil's thorn) is used medicinally as a tonic for diarrhea and diseases of the throat and eyes. The work of Adimoelja [51] in Indonesia and Adaikan [52] in Singapore has drawn attention to a potential additional use of the extracts from $T$. terrestris. These researchers have presented evidence that protodioscin, a compound present in the T. terrestris extracts, can improve sexual desire and enhance erection. A commercial preparation of the T. terrestris preparation is sold under the trade name of Libilov.

\section{Ginseng from Panex ginseng}

The herbal tonic known commonly as ginseng enjoys extremely widespread use. Some chemical evidence supports the stimulatory action of the extract from $P$. ginseng or Panex quinquefolius, but the US Food and Drug Administration (FDA) have found no evidence of enhanced sexual experience resulting from its ingestion [51]. Earlier studies on Korean red ginseng [52] are in-line with the conclusions of the FDA and the authors state that "no complete remission of E-D was noted, but partial responses were reported." Root extracts of ginseng contain a variety of compounds such as steroids, peptides, triterpenoidal d-glucosides, and specifically panax sapogenin.

\section{Lipidic extract from Lepidium meyenii (maca)}

The plant L. meyenii belongs to the Solanaceae and has been known and used in the Andean mountains for 2000 years. While it has nutritional value it is also employed by the Andean Indians for enhancing fertility and sexual behavior in both sexes [53].

\section{Eurycoma longifolia extracts}

E. longifolia (Simaroubaceae), commonly called Tongkat Ali, is native to the jungle of Malaysia [54]. Antimalarial, cytotoxic, anti-ulcer, and antipyretic properties have been claimed for it over the years. Recently, it has figured prominently in the popular press on account of its reputed use to increase male virility. For this reason, several research groups have examined it for this property, notably using sexually experienced male rats [54]. It was found that rats treated with a specific dose of the extract, twice a day, displayed behavior of rats with enhanced sexual arousal [54].

\section{Herbal medicine catuama}

The combination of herbs, collectively known as "Catuama" in Brazil, consists of four plants cupana, Trichilia catigua, Zingiber officinalis and Ptychopetalum olacoides $[55,56]$. The individual components have also been used, separately, for centuries, for a variety of purposes (analgesic, antibacterial, cardiotonic, purgative, and vasodilatory). However, it is the combination of the four that, in more recent times, has been promoted as an aphrodisiac.

\section{CONCLUSION}

Raising the penis from a dependent position to an erect position is a complex neurovascular event modulated by psychological factors and hormonal status. ED is an important public health problem affecting over half of all men ages 40-70. Sildenafil offers the first orally effective symptomatic treatment of ED. Oral sildenafil therapy, while effective in circumventing the cause of ED, provides only short-term symptomatic relief of the condition. Whole patient management of ED might also include psychological or relationship counseling, treatment of associated underlying chronic conditions, and the use of natural agents shown to improve derangements in penile endothelial L-arginine-NO activity. Truly, successful treatment strategies for ED must include the interplay between the mind and the nervous, vascular, and endocrine systems that results in erection.

\section{REFERENCES}

1. Korenman SG. New insights into erectile dysfunction: A practical approach. Am J Med 1998;105(2):135-44. 
2. Halvorsen JG, Metz ME. Sexual dysfunction, Part I: Classification, etiology, and pathogenesis. J Am Board Fam Pract 1992;5(1):51-61.

3. Araujo AB, Durante R, Feldman HA, Goldstein I, McKinlay JB. The relationship between depressive symptoms and male erectile dysfunction: Cross-sectional results from the Massachusetts Male Aging Study. Psychosom Med 1998;60(4):458-65.

4. Melman A, Gingell JC. The epidemiology and pathophysiology of erectile dysfunction. J Urol 1999;161(1):5-11

5. De Leo D, Magni G. Sexual side effects of antidepressant drugs. Psychosomatics 1983;24(12):1076-82.

6. McKinlay JB. The worldwide prevalence and epidemiology of erectile dysfunction. Int J Impot Res 2000;12 Suppl 4:S6-11.

7. Laumann EO, West S, Glasser D, Carson C, Rosen R, Kang JH. Prevalence and correlates of erectile dysfunction by race and ethnicity among men aged 40 or older in the United States: From the male attitudes regarding sexual health survey. J Sex Med 2007;4(1):57-65.

8. Andersson KE, Wagner G. Physiology of penile erection. Physiol Rev 1995;75(1):191-236.

9. Andersson KE. Pharmacology of penile erection. Pharmacol Rev 2001:53(3):417-50.

10. Cirino G, Fusco F, Imbimbo C, Mirone V. Pharmacology of erectile dysfunction in man. Pharmacol Ther 2006;111(2):400-23.

11. Ponholzer A, Temml C, Mock K, Marszalek M, Obermayr R, Madersbacher S. Prevalence and risk factors for erectile dysfunction in 2869 men using a validated questionnaire. Eur Urol 2005;47(1):80-5.

12. Saenz de Tejada I, Carson MP, de las Morenas A, Goldstein I, Traish AM. Endothelin: Localization, synthesis activity and receptor types in human penile corpus cavernosum. Am J Physiol 1991;261:H1078-85.

13. Feldman HA, Johannes CB, Derby CA, Kleinman KP, Mohr BA, Araujo $\mathrm{AB}$, et al. Erectile dysfunction and coronary risk factors: Prospective results from the Massachusetts male aging study. Prev Med 2000;30(4):328-38.

14. Chung WS, Sohn JH, Park YY. Is obesity an underlying factor in erectile dysfunction? Eur Urol 1999;36(1):68-70.

15. Mikhailidis DP, Ganotakis ES, Papadakis JA, Jeremy JY. Smoking and urological disease. J R Soc Promot Health 1998;118(4):210-2.

16. Ledda A. Cigarette smoking, hypertension and erectile dysfunction. Curr Med Res Opin 2000;16 Suppl 1:s13-6.

17. Goldstein I, Lue TF, Padma-Nathan H, Rosen RC, Steers WD, Wicker PA. Oral sildenafil in the treatment of erectile dysfunction. Sildenafil Study Group. N Engl J Med 1998;338(20):1397-404.

18. Moncada I, Jara J, Subirá D, Castaño I, Hernández C. Efficacy of sildenafil citrate at 12 hours after dosing: Re-exploring the therapeutic window. Eur Urol 2004:46(3):357-60.

19. Brock GB, McMahon CG, Chen KK, Costigan T, Shen W, Watkins V, et al. Efficacy and safety of tadalafil for the treatment of erectile dysfunction: Results of integrated analyses. J Urol 2002;168:1332-6.

20. Porst H, Padma-Nathan H, Giuliano F, Anglin G, Varanese L, Rosen R. Efficacy of tadalafil for the treatment of erectile dysfunction at 24 and 36 hours after dosing: A randomized controlled trial. Urology 2003;62(1):121-5.

21. Hellstrom WJ, Gittelman M, Karlin G, Segerson T, Thibonnier M, Taylor T. Sustained efficacy and tolerability of vardenafil, a highly potent selective phosphodiesterase Type 5 inhibitor, in men with erectile dysfunction: Results of a randomized, doubleblind, 26-week placebo-controlled pivotal trial. Urology 2003;61 4 Suppl 1:8-14.

22. Bischoff E, Schneider K. A conscious-rabbit model to study vardenafil hydrochloride and other agents that influence penile erection. Int $\mathrm{J}$ Impot Res 2001;13(4):230-5.

23. Brant WO, Bella AJ, Lue TF. Treatment options for erectile dysfunction. Endocrinol Metab Clin North Am 2007:36(2):465-79.

24. Kloner RA. Erectile dysfunction and cardiovascular risk factors. Urol Clin North Am 2005;32(4):397-402, v.

25. Jackson G, Rosen RC, Kloner RA, Kostis JB. The second Princeton consensus on sexual dysfunction and cardiac risk: New guidelines for sexual medicine. J Sex Med 2006;3(1):28-36.

26. Zhang X, Feng Q, CoteRH. Efficacy and selectivity of phosphodiesterasetargeted drugs in inhibiting photoreceptor phosphodiesterase (PDE6) in retinal photoreceptors. Invest Ophthalmol Vis Sci 2005;46(9):3060-6.

27. Dula E, Bukofzer S, Perdok R, George M; Apomorphine SL Study Group. Double-blind, crossover comparison of $3 \mathrm{mg}$ apomorphine SL with placebo and with $4 \mathrm{mg}$ apomorphine SL in male erectile dysfunction. Eur Urol 2001;39(5):558-3.

28. Goldstein I, Payton TR, Schechter PJ. A double-blind, placebocontrolled, efficacy and safety study of topical gel formulation of $1 \%$ alprostadil (Topiglan) for the in-office treatment of erectile dysfunction. Urology 2001;57(2):301-5.
29. Cookson MS, Nadig PW. Long-term results with vacuum constriction device. J Urol 1993;149(2):290-4.

30. Jarow JP, Nana-Sinkam P, Sabbagh M, Eskew A. Outcome analysis of goal directed therapy for impotence. J Urol 1996;155(5):1609-12.

31. Levine LA, Dimitriou RJ. Vacuum constriction and external erection devices in erectile dysfunction. Urol Clin North Am 2001;28(2):335-41, ix-x.

32. Hellstrom WJ, Bennett AH, Gesundheit N, Kaiser FE, Lue TF, Padma-Nathan $\mathrm{H}$, et al. A double-blind, placebo-controlled evaluation of the erectile response to transurethral alprostadil. Urology 1996;48(6):851-6.

33. Padma-Nathan H, Hellstrom WJ, Kaiser FE, Labasky RF, Lue TF, Nolten WE, et al. Treatment of men with erectile dysfunction with transurethral alprostadil. Medicated Urethral System for Erection (MUSE) Study Group. N Engl J Med 1997;336(1):1-7.

34. Williams G, Abbou CC, Amar ET, Desvaux P, Flam TA, Lycklama à Nijeholt GA, et al. Efficacy and safety of transurethral alprostadil therapy in men with erectile dysfunction. MUSE Study Group. Br J Urol 1998;81(6):889-94.

35. Bodner DR, Haas CA, Krueger B, Seftel AD. Intraurethral alprostadil for treatment of erectile dysfunction in patients with spinal cord injury. Urology 1999;53(1):199-202.

36. Lewis RW. Transurethral alprostadil with MUSE (medicated urethral system for erection) vs intracavernous alprostadil--a comparative study in 103 patients with erectile dysfunction. Int J Impot Res 1998;10(1):61-2

37. Traish AM, Goldstein I, Kim NN. Testosterone and erectile function: From basic research to a new clinical paradigm for managing men with androgen insufficiency and erectile dysfunction. Eur Urol 2007;52(1):54-70

38. Saleh DO, El-Awdan SA, Nofel SM, El-Eraky WI, El-Khatib AS, Kenawy SA. Estrogens improve the cardiovascular alterations in fructose-induced insulin resistant ovariectomized rats. Int J Pharm Pharm Sci 2015;7(7):241-7.

39. Jain P, Rademaker AW, McVary KT. Testosterone supplementation for erectile dysfunction: Results of a meta-analysis. J Urol 2000;164(2):371-5.

40. Shabsigh R, Kaufman JM, Steidle C, Padma-Nathan H. Randomized study of testosterone gel as adjunctive therapy to sildenafil in hypogonadal men with erectile dysfunction who do not respond to sildenafil alone. J Urol 2004;172(2):658-63.

41. Mulcahy JJ, Austoni E, Barada JH, Choi HK, Hellstrom WJ, Krishnamurti S, et al. The penile implant for erectile dysfunction. J Sex Med 2004;1(1):98-109.

42. Wilson S, Delk JR $2^{\text {nd }}$, Henry GD, Siegel AL. New surgical technique for sphincter urinary control system using upper transverse scrotal incision. J Urol 2003;169(1):261-4

43. Lee JH, Cho SH, Kim JY, Park HJ, Do JA, Baek S. Determination and quantification of nine adulterant local anaesthetics in illegal treatments for male premature ejaculation by GC-FID and GC-MS. Int J Pharm Pharm Sci 2016;8(3):135-40.

44. Montorsi F, Rigatti P, Carmignani G, Corbu C, Campo B, Ordesi G, et al. AMS three-piece inflatable implants for erectile dysfunction: A long-term multi-institutional study in 200 consecutive patients. Eur Urol 2000;37(1):50-5

45. Feldman HA, Goldstein I, Hatzichristou DG, Krane RJ, McKinlay JB. Impotence and its medical and psychosocial correlates: Results of the Massachusetts Male Aging Study. J Urol 1994:151(1):54-61.

46. Reiter WJ, Pycha A, Schatzl G, Pokorny A, Gruber DM, Huber JC, et al. Dehydroepiandrosterone in the treatment of erectile dysfunction: A prospective, double-blind, randomized, placebo-controlled study. Urology 1999;53(3):590-4.

47. Ernst E, Pittler MH. Yohimbine for erectile dysfunction: A systematic review and meta-analysis of randomized clinical trials. J Urol 1998;159(2):433-6.

48. Guirguis WR. Oral treatment of erectile dysfunction: From herbal remedies to designer drugs. J Sex Marital Ther 1998;24(2):69-73.

49. Zaher TF. Papaverine plus prostaglandin E1 versus prostaglandin E1 alone for intracorporeal injection therapy. Int Urol Nephrol 1998;30(2):193-6

50. Junemann KP, Alken P. Pharmacotherapy of erectile-dysfunction. Int J Impot Res 1989:1:71-93.

51. Adimoelja A. Phytochemicals and the breakthrough of traditional herbs in the management of sexual dysfunctions. Int $\mathrm{J}$ Androl 2000;23 Suppl 2:82-4

52. Adaikan PG, Gauthaman K, Prasad RN, Ng SC. Proerectile pharmacological effects of Tribulus terrestris extract on the rabbit 
corpus cavernosum. Ann Acad Med Singapore 2000;29(1):22-6.

53. Choudhary I, Ur-Rahman A. Elixirs of love. Chem Br 1997;33:25-7.

54. Choi HK, Seong DH, Rha KH. Chemical efficiency of Korean red ginseng for erectile-dysfunction. Int J Impot Res 1995;7(3):181-6.
55. Muhammad I, Zhao J, Dunbar DC, Khan IA. Constituents of Lepidium meyenii 'maca'. Phytochemistry 2002;59(1):105-10.

56. Ang HH, Sim MK. Eurycoma longifolia JACK and orientation activities in sexually experienced male rats. Biol Pharm Bull 1998;21(2):153-5. 